\section{Evaluation of a head mounted camera for clinical dental teaching}

\author{
R. G. Chadwick, ${ }^{1}$ A. P. Carena, ${ }^{2}$ B. Hunter ${ }^{3}$ and K. Campbell ${ }^{4}$
}

IN BRIEF
This paper evaluates a head mounted
camera for use in clinical teaching.
The device improved the level of detail
observed during dental procedures,
and the level of feedback to learners.
It also provided better learner support
by both enabling the learner to observe
a dental procedure being undertaken
from the viewpoint of the operator and
permitting the teacher to view a learner
undertaking a procedure.

\begin{abstract}
Objective To evaluate the potential of a novel head mounted camera to both improve the level of detail observed by learners/teachers observing dental procedures being undertaken and to improve the level of feedback given to learners. Design Questionnaire. Subjects and methods Qualified members of the dental team and those in training evaluated the usefulness of the application of a novel head mounted camera in their clinical teaching within Dundee Dental School and Hospital. Results A total of 210 questionnaires were issued and received for analysis. Although the device generally improved the level of detail observed by learners/teachers and improved the level of feedback given to learners, there was scope for improving upon image quality. The lighting of the environment in which the camera was used was a critical factor in optimising success. The different members of the dental team displayed different expectations of the device. This was attributed in part to their level of previous exposure to clinical work. In applying this technology it is therefore important to understand the needs of the user. Conclusions The camera system did enhance the learning experience but required further refinement in relation to image quality.
\end{abstract}

\section{INTRODUCTION}

It is well known that watching a clinical procedure being undertaken either in real time or upon playback is a valuable teaching aid for both teacher and learner. ${ }^{1,2}$ Traditionally this has been achieved by either small groups of students observing a qualified dentist treating a patient or the dental teacher watching a student carry out a procedure. Neither situation is ideal for the confined space of the oral cavity compromises the view. Furthermore it is incredibly labour intensive to watch a student perform an entire operative procedure from start to finish. Although observing a procedure at predefined interim stages (such as cavity prepa-

${ }^{*}$ Clinical Senior Lecturer and Hon Consultant in Restorative Dentistry, The Dental School, Dundee; ${ }^{2}$ Deputy Head of Instrumentation, ${ }^{3}$ Technician in Charge of Electronics, R \& D Section, ${ }^{4}$ Technician, R \& D Section, Department

of Medical Physics, Ninewells Hospital, Dundee

${ }^{*}$ Correspondence to Dr R. G. Chadwick

Email r.g.chadwick@dundee.ac.uk

\section{Refereed Paper}

Accepted 23 October 2007

DOI: $10.1038 /$ bdj.2008.10

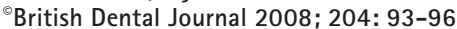

ration, lining and restoration) is commonly used to optimise the use of staff resources, only snapshots of performance are gleaned. Valuable opportunities for learner support are thus missed and the teacher has little idea of how the end point was achieved.

Although the dental literature does contain a number of technical reports on camera systems in clinical teaching, surprisingly little has been reported on the student perception of the use of close up cameras in clinical teaching. Gillings ${ }^{3}$ found such technology helpful to enhance the student experience when demonstrating dental technology and in addressing the teaching of large classes. Robinson and Lee $^{4}$ and Britto et al. ${ }^{1}$ both showed that watching a clinical procedure being undertaken either in real time or on playback of a video was a valuable teaching aid. Giving videotape feedback to learners on their performance in carrying out a clinical procedure is also said to be of great benefit. ${ }^{2}$ All of these papers, with the exception of Kardash and Tessler, ${ }^{2}$ focussed on the teacher demonstrating to students. We therefore sought to evaluate, in Dundee Dental
School and Hospital, a head mounted video camera system (Fig. 1) developed by the authors and the Medical Physics Department of Ninewells Hospital, Dundee to determine its usefulness both for teacher demonstration and assessment of students carrying out operative procedures. We specifically sought to see if this technology:

- Improved the level of detail observed when observing dental procedures being undertaken

- Improved the level of feedback to learners

- Provided better learner support.

\section{MATERIAL AND METHODS}

The camera evaluated in this study (Fig. 1) was mounted upon a headband worn by the student or staff operator. Illumination of the operating area was provided by two bright white LED headlamps. A small red laser beam allowed the wearer to target the camera upon the area of work. For portability this was all battery powered and a radiofrequency transmitter, incorporated in the device, permitted real time images to be sent to a receiver for display on either a monitor or capture 
on a recording device for later playback. This arrangement obviated the need for trailing cables. Inertia sensors, incorporated into the headband, triggered a freeze frame mechanism on the display monitor, so that rapid head movements of the wearer did not result in sea sickness of the observers. The associated sensory conflict, from such head movements, has been reported to induce motion sickness in pilots using helmet mounted displays (HMDs). ${ }^{5}$ Although the red guide laser beam was safe to the eye all patients on whom the device was used wore laser safety glasses to ensure optimum protection.

This work commenced in 2004. A telephone call to the Secretary to our local Medical Research Ethics Committee revealed that research ethics approval was not required for this work as it utilised commercially available equipment, albeit in novel combination, and formed part of taught course evaluation. A questionnaire was devised (by means of a focus group of all potential users) to evaluate usefulness of the camera in clinical teaching. It was piloted and then finalised in a form that was suitable for all members of the dental team to complete from the perspectives of either device wearer or viewer. It consisted of a series of statements to which the respondent was requested to indicate their level of agreement by means of a 5 point Likert Scale $(1=$ strongly disagree, 2 = disagree, 3 = neither agree nor disagree, $4=$ agree and 5 = strongly agree) . It was so constructed that statements on device evaluation were kept separate from suggestions for technical modi fications. This was thought important for perceptions are known to influence our evaluation of service quality. ${ }^{6}$ To maximise the comprehensiveness of the evaluation space was left for free text comments. Any improvement suggestions were categorised and articulated to the device design team to assist in further development and refinement. The statements may be viewed in Table 1 .

A relational database was created using Paradox (Paradox Version 3.5, Borland International, CA 95067-0001, USA) for data input, from the completed questionnaires, and flexible interrogation. Subsequent statistical analyses

\section{Table 1 Summary of all questionnaire responses}

\begin{tabular}{|c|c|c|c|c|}
\hline Statement & Mean (S.D.) & $n$ & $\begin{array}{l}\text { Median } \\
\text { \&t Mode }\end{array}$ & Comment \\
\hline $\begin{array}{l}\text { This technology enhances my learning/ } \\
\text { teaching experience }\end{array}$ & $4.01(0.72)$ & 203 & 4,4 & (:) \\
\hline $\begin{array}{l}\text { I found the picture quality adequate for } \\
\text { the purpose. }\end{array}$ & 3.41 (0.99) & 197 & 4,4 & \\
\hline $\begin{array}{l}\text { The images were sufficiently stable for } \\
\text { me to see what was going on. }\end{array}$ & 3.57 (0.93) & 194 & 4,4 & \\
\hline $\begin{array}{l}\text { I can see what is going on better than } \\
\text { watching from the chairside }\end{array}$ & $3.77(1.06$ & 182 & 4,4 & (:) \\
\hline $\begin{array}{l}\text { This technology hinders my learning/ } \\
\text { teaching experience. }\end{array}$ & $2.02(0.99)$ & 193 & 2,2 & (:) \\
\hline $\begin{array}{l}\text { This technology lets me monitor more } \\
\text { closely what the operator is doing. }\end{array}$ & $3.98(0.80)$ & 181 & 4,4 & ;) \\
\hline $\begin{array}{l}\text { Playing back images of the procedure } \\
\text { helps improve the quality of feedback } \\
\text { given/received. }\end{array}$ & $3.90(0.69)$ & 140 & 4,4 & (:) \\
\hline $\begin{array}{l}\text { The camera was comfortable to wear } \\
\text { once I got used to it. }\end{array}$ & $3.26(1.01)$ & 91 & 3,4 & \\
\hline The laser light guide was distracting. & $2.82(1.05)$ & 145 & 3,2 & \\
\hline $\begin{array}{l}\text { In its present form the technology was } \\
\text { easy to use. }\end{array}$ & 3.15 (1.02) & 111 & 3,4 & \\
\hline $\begin{array}{l}\text { This technology offers no benefit to the } \\
\text { learner/teacher. }\end{array}$ & 1.93 (0.92) & 181 & 2,2 & (:) \\
\hline $\begin{array}{l}\text { The equipment improves communication } \\
\text { between teacher and learner. }\end{array}$ & $3.84(0.73)$ & 169 & 4,4 & ;) \\
\hline $\begin{array}{l}\text { I found using this technology } \\
\text { intimidating (ie people watching what I } \\
\text { am doing). }\end{array}$ & $2.40(1.06)$ & 107 & 2,2 & (:) \\
\hline $\begin{array}{l}\text { To see a procedure carried out in the } \\
\text { line of vision of the teacher/operator is } \\
\text { extremely helpful. }\end{array}$ & $4.16(0.72)$ & 172 & 4,4 & (:) \\
\hline
\end{tabular}

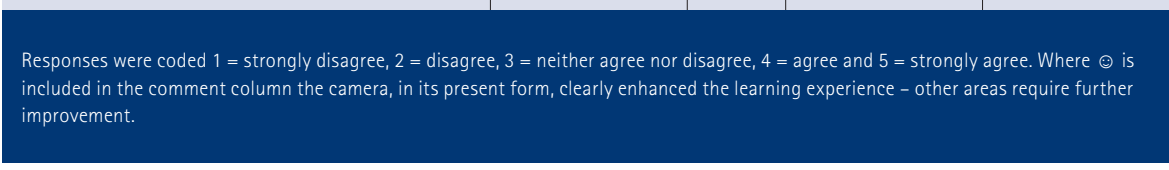

Table 2 Future developments - Breakdown of all responses

\begin{tabular}{|c|c|c|c|}
\hline Statement & Mean (S.D.) & $\mathrm{n}$ & Median \& Mode \\
\hline $\begin{array}{l}\text { It would be useful to be able to } \\
\text { record/playback Video. }\end{array}$ & $4.19(0.59)$ & 183 & 4,4 \\
\hline $\begin{array}{l}\text { It would be useful to have the capacity to } \\
\text { communicate directly with a teacher/student via an } \\
\text { earpiece whilst a procedure is carried out }\end{array}$ & $3.59(0.96)$ & 168 & 4,4 \\
\hline
\end{tabular}




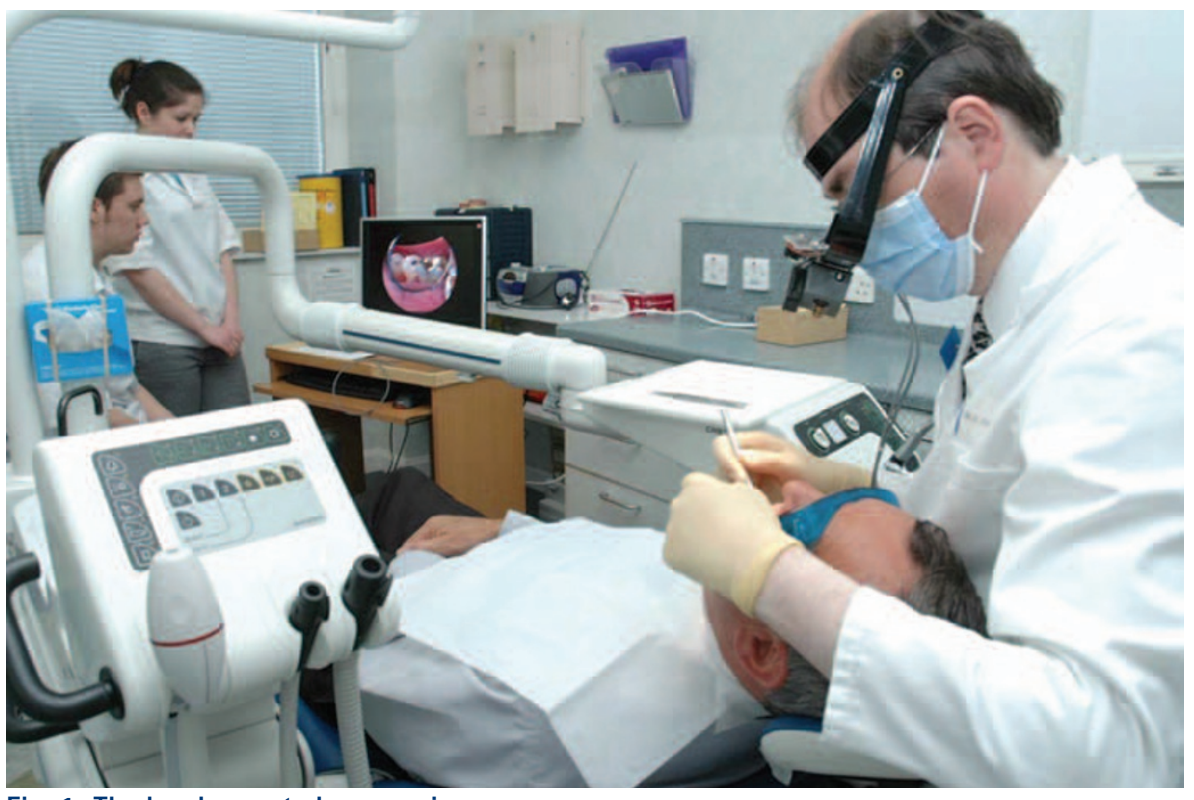

Fig. 1 The head mounted camera in use

Table 3 Breakdown of environments and circumstances in which camera was evaluated

\begin{tabular}{l|l|l}
\hline Environment & Number of responses & Comments \\
\hline $\begin{array}{l}\text { Clinical } \\
\begin{array}{l}\text { Operative } \\
\text { Techniques } \\
\text { Laboratory }\end{array}\end{array}$ & 82 & $\begin{array}{l}\text { Adequate lighting, various operators } \\
\text { demonstrating cavity preparation to } \\
\text { dental students }\end{array}$ \\
\hline $\begin{array}{l}\text { Operative } \\
\text { Techniques } \\
\text { Laboratory }\end{array}$ & 12 & $\begin{array}{l}\text { Adequate lighting, inexperienced camera operator } \\
\text { demonstrating to therapy students }\end{array}$ \\
\hline $\begin{array}{l}\text { Prosthetics } \\
\text { Teaching laboratory }\end{array}$ & 12 & $\begin{array}{l}\text { Poor lighting, new operators demonstrating } \\
\text { partial denture Surveying to colleagues and } \\
\text { Dental students }\end{array}$ \\
\hline $\begin{array}{l}\text { Prosthetics } \\
\text { Production } \\
\text { Laboratory }\end{array}$ & 12 & $\begin{array}{l}\text { Good bench lighting. Technicians demonstrating } \\
\text { denture wax up to colleagues }\end{array}$ \\
\hline $\begin{array}{l}\text { Restorative } \\
\text { Production } \\
\text { Laboratory } \\
\begin{array}{l}\text { Skills phantom } \\
\text { Head laboratory }\end{array}\end{array}$ & $\begin{array}{l}\text { Good bench lighting. Technicians demonstrating } \\
\text { male female components of bridgework and also } \\
\text { Porcelain build up of crowns. }\end{array}$ \\
\hline $\begin{array}{l}\text { Good clinical lighting, Teachers of conservative } \\
\text { dentistry demonstrating and viewing head camera } \\
\text { to one another for first time. }\end{array}$ \\
\hline
\end{tabular}

Table 4 Breakdown of questionnaire returns according to designation of respondent

\begin{tabular}{l|l}
\hline Designation of respondent & Number of returns \\
\hline Dental student & 125 \\
\hline Dental instructor/technician & 22 \\
\hline Dental nurse & 3 \\
\hline Dental therapy students & 11 \\
\hline Dental SHO/SPR & 7 \\
\hline Dentist (other than specified above) & 37 \\
\hline
\end{tabular}

were performed using statistical programs within Excel (Sample Descriptive Statistics) and Prism (GraphPad Prism ${ }^{\circledR}$, Version 4, GraphPad Software Inc., San Diego, CA 92121, USA)(Non parametric One Way Analyses of Variance Kruskal-Wallis Analysis of Variance by Ranks and Dunn's Multiple Comparison Post Testing). The threshold for statistical significance of all comparative tests was a $\mathrm{P}$ value of less than 0.05 .

\section{RESULTS}

A total of 210 completed questionnaires were received for analysis. Due to both the multi-functionality of the questionnaire employed and the failure to complete all relevant sections by some the numbers of respondents in the results tables does not always correspond to this total.

Table 1 summarises the number of responses, mean, mode and median scores for each evaluation aspect of the questionnaire. The symbol $;$ is used to identify those areas where the device was successful in achieving its educational aims. It should be noted, however, that in the other areas the device was broadly helpful but clearly further improvement work was required to bring the user experience up to the level achieved in the areas marked $\odot$. Table 2 summarises the number of responses, mean, mode and median scores for the future development aspect of the questionnaire. It is clear that the respondents feel that it would be useful to be able to record/ playback video and would perhaps like the capacity to communicate by means of an earpiece with a teacher/student whilst carrying out a procedure.

Table 3 summarises the environments and circumstances in which the camera was evaluated. One way non parametric analyses of variance by ranks, using the Kruskal-Wallis test, indicated statistically significant effects of environment/circumstance for the response to all evaluation questions at $\mathrm{P}<0.001$ with the exception of question $8(\mathrm{P}<0.05)$ and questions 7, 9 and 10 ( $\mathrm{P}<0.05)$. Subsequent localisation using Dunn's Multiple Comparison Test indicated camera operator inexperience and less than ideal lighting to be the major factors contributing to a less than ideal experience.

Table 4 gives a breakdown of the 
questionnaire returns according to the designation of respondent. One way non parametric analyses of variance by ranks, using the Kruskal-Wallis test with localisation using Dunn's post testing, of questionnaire responses according to the designation of returnee, demonstrated significantly different responses for dental therapy students compared to other groups. These related to questions 2, 3, 4 and 6 and also in their response to questions on future developments. Therapists were more dissatisfied ( $P$ $<0.05)$ with the image quality than dental students and instructors/technicians allocating a median score of 2 compared to 4. They were more concerned about the stability of the image $(\mathrm{P}<0.01)$ than the dental instructor/technicians, median rating this as 3 compared to 4 . They could see little advantage of playing back images to enhance the learning experience $(\mathrm{P}<0.01)$, compared to the dental instructor/technicians who gave a median score of 4 compared to the 3 of the therapists, and were less impressed $(\mathrm{P}<0.001)$ with the ability of the camera to help them monitor more closely what the operator was doing than both the dental students and dental instructor/technicians (whose median scores were 4 compared to 3 for the therapists). With specific reference to possible future developments the therapists, although supportive (median score 4) of developing video playback were less so $(\mathrm{P}<0.05)$ than the SHO/SPR's (median score 5). They were however neutral (median score 3) on developing earpiece communication between teacher/student whilst carrying out clinical procedures.
In this regard the dental technicians were significantly more receptive to this development than the therapists ( $P$ $<0.05$ ) (median score 4).

Free text comments were made by 37 respondents in the space left for this purpose in the questionnaire. The majority of these offered advice on the design of the head camera to make it easier to wear. Other comments requested improvements in image resolution.

\section{DISCUSSION}

In general this technology improved the level of detail observed when dental procedures were undertaken. It also enhanced the level of feedback that could be given to learners undertaking operative procedures. Its potential to enhance learning in a variety of environments was demonstrated. This agrees well with previous reports on the usefulness of static camera systems in clinical teaching. ${ }^{1-4}$ It is however important to note an absolute requirement of adequate lighting to ensure success. As is evident from the evaluation this was not always achieved in all the environments where the device was used. Although in common with others ${ }^{1}$ there is a need to improve image resolution of the system to optimise the learning experience, it is pleasing to note that image stability, despite the camera being mounted on the head, does not appear to be a problem. Video camera technology is rapidly advancing and it is therefore possible to improve upon the present equipment by replacing the original camera with a more up to date model.

A challenge to potential users, and of some interest, is the different perceptions of this technology by the various members of the dental team. To some extent this may be a consequence of the different environments in which it was applied. It could also be possible that the previous chairside experiences of the therapy students, who had all previously worked as dental nurses and would have observed many clinical procedures closely, made the application of this technology less relevant to this group. Notwithstanding this the system did achieve its aims and further refinement and development, in light of the experiences reported here, is underway. This will involve the use of focus groups.

This evaluation was funded by a miniproject grant awarded by the Learning and Teaching Support Network (LTSN 01 - Mini Project 24). The work reported here would not have reached fruition without the support of the engineering students Marco Steinberg and Jan Hoppner of the Technische University of Ilmenau, Germany who built and maintained the head mounted camera system. We are also grateful to Mr Mark Tulley (retired Principal Medical Physicist) for camera development and also to Professor W. P. Saunders, Dean of Dentistry, for funding in part the cameras development. Finally we thank all staff and students who participated in the evaluation.

1. Britto LR, Veazey W S, Manasse G R. (2004) Personal video monitor as an accessory to dental operating microscopes. Quintessence Int 2004; 35: 151-154.

2. Kardash K, Tessler M J. Videotape feedback in teaching laryngoscopy. Can J Anaesth 1997; 44: 54-58.

3. Gillings B R. The use of closed circuit television in the teaching of dental technology. Aust Dent J 1976; 21: 242-246.

4. Robinson P B, Lee J W. The use of real time video magnification for the pre-clinical teaching of crown preparations. Br Dent J 2001; 190: 506-510.

5. Craig G L, Jennings S A, Swail C P. Head roll compensation in a visually coupled HMD: consideration for helicopter operations. Aviat Space Environ Med 2000; 71: 476-484.

6. Chadwick R G. Quality assurance by service quality - an industrial approach to monitoring course delivery. Br Dent J 2002; 192: 285-288. 